Barbara Pregelj ${ }^{1}$

UDK: 821.134.2.09-055.2

Universidad de Nova Gorica

https://doi.org/10.18485/imp.2017.ch.17

Facultad de Humanidades

\title{
EN BÚSQUEDA DE HUELLAS PROPIAS: LITERATURA VASCA CONTEMPORÁNEA ESCRITA POR MUJERES
}

\begin{abstract}
El artículo presenta una visión panorámica de las literaturas que escriben las mujeres del País Vasco tanto en euskera, como también en español y francés. A tenor de un análisis temático de las obras literarias se ha procurado buscar las similitudes y diferencias más destacadas entre las autoras que escriben en tres sistemas literarios distintos, determinados por el uso de las lenguas respectivas.
\end{abstract}

Palabras clave: literaturas vascas, literatura de mujeres, análisis temático, Euskara, Español, Francés

El reto de entender la complejidad del Euskal Herria actual es enorme. Si solo nos limitáramos a intentar describir una pequeña parte de la realidad lingüística de las siete provincias en las que se hablan y escriben el euskera, el castellano y el francés, centrándonos sobre todo en el euskera, partiendo del proceso de su normalización en los años 60 del siglo pasado, pasando por las diferencias dialectales y terminar con la fuerte influencia del castellano y francés en él, el espacio destinado a esta reflexión se nos haría corto. No obstante, algunas observaciones preliminares son necesarias para enmarcar la panorámica que en este artículo me propongo hacer, ya que la práctica de determinar el objeto de investigación es un lugar común de muchas de las reflexiones sobre la literatura vasca. Se trata, pues, de una literatura pequeña, minoritaria, tardía (Olaziregi, Pregelj 2010: 149) con características específicas que conciernen tanto su periodización (Lasagabaster 1987; Aulestia 1992), como su carácter específico (Juaristi 1987; Salaberri 2002; Aldekoa 2004). Puesto

$1 \quad$ barbara.pregelj@guest.arnes.si 
que a partir del siglo XVI en el contexto español los creadores cada vez más se determinan por su lengua (Guillen 1998), también las historias de literatura vasca, señala Estibalitz Ezkerra Vegas, a partir de Koldo Mitxelena en sus estudios se centran ante todo en la literatura escrita en euskera. Como ha observado la citada investigadora estadounidense siguiendo las reflexiones de Mitxelena, el sintagma "euskal literatura" no es sinónimo de "literatura vasca", ya que el primero se utiliza para designar solo la literatura escrita en euskera (www.basqueliterature.com).

Sin embargo, sostiene Ezkerra Vargas cuya opinión comparto, "esta visión obvia la realidad de los ciudadanos y las ciudadanas vascas, que no sólo hablan euskara. En otras palabras, apunta hacia una nación que no se corresponde con la realidad de los sujetos que pueblan el territorio; muestra en singular una realidad que es lingüísticamente plural (y con el tiempo, lo será aún más)." (Ezkerra Vegas²). Por lo cual, para ser fiel a esta pluralidad, la panorámica de la literatura escrita por mujeres que ofrezco a continuación, va a esbozar las líneas principales de los tres sistemas literarios en los que actualmente se desarrollan las literaturas vascas: la que se escribe en euskera, la del castellano y la que está escrita en francés.

\section{Literatura de mujeres que escriben en euskera}

En actualidad, sostiene Eva Larraurari, en euskera escriben tres generaciones de escritores: los que empezaron a introducir en ella las corrientes modernas, si bien lo hacían, como sostiene Ramón Saizarbitoria (1944), "para que hubiera escritores vascos. /Yo/ era un amateur de la literatura, como lo fuimos del teatro o de la política. Trataba de traer a la literatura vasca lo que veíamos en el mundo que nos rodeaba para sacarla del atraso." (citado por Larraurari 2013). Junto con los autores nacidos en los años cuarenta y cincuenta, formados en los años setenta, como, por ejemplo Anjel Lertxundi (1944), Arantxa Urretabizkaia (1947), Joseba Sarrionandia (1958), entre los cuales, según las palabras de Bernardo Atxaga (1951), "hubo un empaste inesperado entre lo que en el mundo se con-

Cito su artículo publicado en basqueliterature.com. 
sideraba moderno y la cultura vasca" (citado por Larraurari 2013), empieza a obtener reconocimiento tanto nacional como internacional la generación nacida en los setenta, cuyos representantes más destacados son Kirmen Uribe (1970), Unai Elorriaga (1973) y Harkaitz Cano (1975). Como reconoce Uribe: "Atxaga demostró que es posible ser escritor en euskera, ser leído y ser traducido. Nos dio ilusión a la comunidad y a los autores" (citado por Larrauraru 2013). Las voces nuevas, las de la creación más reciente, son sobre todo las de las mujeres: Garazi Goia (1978), Irati Elorrieta (1979), Eider Rodríguez (1977), Uxue Alberdi (1984), Irati Jiménez (1977), Katixa Agirre (1981) y Karmele Jaio (1970).

Según los estudios llevados a cabo por Mari José Olaziregi, solo un 10\% de autores del País Vasco son mujeres (Olaziregi 2001: 466), o en palabras de Karmele Jaio: “Las mujeres no somos más del 15\% de los escritores en euskera. No solo es un derecho que publiquemos sino que es necesario para completar una literatura con el punto de vista de las mujeres. Las experiencias de las mujeres, las relaciones personales están entrando en las historias que cuentan las nuevas autoras". (Citado por Larraurari 2013). ¿Se puede buscar un denominador temático común entre ellas?

Arantxa Urretabaizkaia es la única mujer entre los autores de la primera generación que empezó a escribir dentro del círculo de la editorial Lur para modernizar la literatura escrita en euskera. Aunque su debut literario se dio en el campo de la poesía, es reconocida sobre todo por su narrativa. Su primera novela Zergatik Panpox ${ }^{3}$ (¿Por qué, Panpox?, 1979) es una historia de una madre y su hijo abandonados, narrada en un día en forma de un monologo interior. En las siguientes novelas su estilo varia del realismo en Saturno (1987) al lirismo y la nivelización del relato en Koaderno gorria (Cuaderno rojo, 1998). Aunque Urretabizkaia aborda y parte desde los temas relacionados con las mujeres (conflicto entre la maternidad, la militancia social y política en Koaderno gorria; la vejez y la necesidad de buscar las nuevas formas de envejecer en 3 Mariak), "definir de esta manera sus obras /.../ supondría quedarse en la superficie" (Ayerbe

3 Para facilitar la lectura todos los títulos de libros se traducen al castellano. Las traducciones que figuran entre paréntesis o seguidas de un guión son provisionales y no significan que todas las obras tienen su traducción en castellano. El año de la publicación que figura al lado del título de la obra se refiere a su primera edición en euskera. 
Sudupe 2012: 257), ya que a la vez la autora "profundiza en el plano social y político de estos temas". (ibidem)

Mariasun Landa (1949) es, a su vez, una reconocida ${ }^{4}$ autora de textos infantiles y juveniles que destacan tanto por su novedad temática (Zure eskua zurean - Mi mano en la tuya, 1996; Katuak bakar-bakarik sentitzen duenean - Cuando los gatos se sienten tan solos, 1998; Krokodiloa ohe azpian - Cocodrilo bajo la cama, 2003) y aproximación al nonsense (Galtzerdi suizida - Calcetín suicida, 2001), como por su experimentación formal: álbum en forma de una carta con un final abierto (Elefante txori-bihotz Elefante corazón de pájaro, 2001), microrelatos (Iholdi, 1988). Además, las protagonistas de sus textos se alejan de imágenes y roles típicos de chicas tal y como que suelen ser reflejadas en la literatura infantil (caracterizadas sobre todo por su postura pasiva, obediente y dócil), ofreciendo modelos distintos a nuevas generaciones de chicas y chicos vascos (Pregelj 2013).

El interés principal de Laura Mintegi (1955) es la indagación en la psique humana: en el amor en sus distintas formas, como el incesto (Bai... baina ez - Sí... pero no, 1986), el amor y el proceso de enamoramiento (Sisifo maite minez - Sisifo enamorado, 2001), en la mente de un torturador (Legez kampo - Fuera de ley, 1991), en las reflexiones de una activista presa (Nerea eta biok - Nerea y yo, 1994) y en las relaciones entre la masculinidad, la sociedad y el amor (Ecce homo, 2006). Miren Lourdes Oñederra (1958) es autora de varios cuentos agrupados en distintas colecciones y una novela Emakumeari sugeak esan zion - Y la serpiente dijo a la mujer, 1999) en la que su protagonista emprende un viaje interior de reconstrucción de la personalidad de la protagonista.

Itxaro Borda (1959) nació en la parte francesa del Pais Vasco, en Baiona, donde también reside, y es autora de una prolífica obra literaria: poesía (Bizitza nola badoan - Como transcurre la vida, 1984; Krokodil bat daukat bihpotzaren ordez - Tengo un cocodrilo en lugar de corazón, 1986; Just love, 1988; Bestaldean - Al otro lado, 1991; Orain - Ahora, 1998; Hautsak errautsak bezain - El polvo al igual que la ceniza, 2002; Noizteka - De vez en cuando, 2007; Medearen iratzartzea - El despertar de

$4 \quad$ Landa fue en 2003 la primera pluma euskalduna en obtener el Premio Nacional de Literatura Infantil y Juvenil para su obra Krokodiloa ohe azpian. 
Medea, 2012), novelas que entiende como un espacio de una dura crítica social (en Basilika, 1984 sociedad anclada en un catolicismo cerrado; varias novelas policíacas que empiezan en 1994 con Bakean utzi arte - Hasta que nos dejan en paz, que tienen como protagonista a la detective Amaia Ezpeldoi y en las que los asesinatos y su esclarecimiento se convierten en un pretexto para criticar la sociedad vasca; $\% 100$ basque - $100 \%$ basque, 2001 es un texto límite entre la novela y el ensayo en el que la autora reflexiona sobre la identidad vasca; en Ezer gabe hobe - Mejor sin nada, 2009 presenta las reflexiones críticas sobre la migración).

La obra de Miren Agur Meabe (1962) tiene carácter totalmente opuesto, ya que se caracteriza por su estilo intimista: si bien es también autora de narrativa (Uneka... gaba - Por momentos... la noche, 1986; Kristalezko begi bat - Ojo de cristal, 2013) y de los textos de narrativa infantil y juvenil (Itsas/abarreko etxea - La casa del acantilado, 2001; Joanes eta Bioletaren bihotza - El corazón de Joanes y Bioleta, 2002; Etxe bitan bizi naiz, eta zer? - Vivo en dos casas, ¿y qué?, 2003; Nola zuzendu andereño gaizto bat - Como corregir a una maestra malvada, 2003; Urtebete itsasargian - Un año en el faro, 2006), la crítica literaria he señalado sobre todo la importancia de sus ocho libros de poesía: en Azalaren kodea - El código de la piel, 2001, sostiene la crítica literaria Iratxe Gutierrez, la protagonista de la poesía es «el yo femenino que habla en primera persona, /tratando/ de librarse de la servidumbre del idioma. Pues ésta condiciona las relaciones con los otros, imposibilitando la comunicación. Es más, la servidumbre hacia el idioma nos lleva al recuerdo, y no podemos zafarnos de los colpes de la memoria. Por eso ve necesario librarse de ese lastre y encontrar otro tipo de sistema, de código, que posibilite a su vez otro tipo de comunicación: se decanta claramente por la piel. Y en ese intento de exteriorizar los sentimientos y las preocupaciones, en lugar de 'despellejarse' optará por la transparencia de la piel; de hecho, cree que es necesario recubrir el cuerpo con un nuevo código» (Gutierrez, Iratxe 2001, citado por Ezkerra5). Arantxa Iturbe (1964) destaca por sus cuentos (Ezer baino lehen - Antes de nada, 1992; Lehenago zen berandu - Ya ni siquiera es tarde, 1995), un ensayo sobre la maternidad (Ai, ama! - Ay, madre, 1999), un libro hibrido que combina la ficción con testimonios de mujeres mayores (Kontu jaten - Pendiente

$5 \quad$ Cito el texto asequible en basqueliterature.com. 
de sus palabras, 2006) y varios textos de literatura infantil y juvenil (Nik eserita egiten dut - Yo lo hago sentado, 2001; Amona basoan galdu zenekoa - Cuando la abuela se perdió en el bosque, 2003; Norak suhiltzaile izan nahi du - Nora quiere ser bombera, 2003).

Karmele Jaio (1970) es autora de varios libros de relatos (Amabost zauri - Quince heridas, 2004; Zu bezain ahul - Tan débil como tú, 2007; Ez naiz ni - No soy yo, 2012) en los que le interesan sobre todo la comunicación en pareja, las relaciones familiares, el concepto de maternidad, la soledad. Es también autora de poesía (Orain hilak ditugu - Ahora tenemos muertos, 2010) y de dos novelas: Amaren eskuak (Las manos de mi madre, 2004) en la que la protagonista intenta compaginar el ciudado de la madre enferma con el de su propia familia en una narración en la que se entretejen el presente y el pasado, y Musika airean (Música en el aire, 2010).

Jasone Osoro (1971) es autora de cuentos (Tentazioak - Tentaciones, 1998; Korapiloak - Desnudos, 2001), novelas (Greta, 2003; Bi marra arrosa - Dos líneas rosas, 2009; 12etan bermuta - Vermut a las 12, 2015) y de muy leidos textos de literatura juvenil. Sus obras para adultos tematizan la alienación en muchas de sus formas, sobre todo a nivel de las relaciones personales.

Eider Rodríguez (1977) es, a su vez, autora reconocida de varios libros de relatos (Eta handik gutxira gaur - Y poco después ahora, 2004; Haragia - Carne, 2007; Katu jendea - Un montón de gatos, 2010), en los que predominan el realismo, el "estilo frío y preciso" (Ayerbe Sudupe 2012: 231) y versan sobre la incomunicación en la sociedad actual, la importancia de las apariencias, el fingimiento. También es autora de un texto de literatura infantil Nikoleta eta gaua (Nicoleta y la noche, 2008).

Irati Jiménez (1977) es autora de narrativa (novelas: Bat, bi, Manchester - Uno, dos, Manchester, 2006; Nora ez dakizun hori - Nora esa que no conoces, 2009; Atsekabe zaitut - Te disgusto, 2010; cuentos: Laranja azalaren negarra - Llanto de piel de naranja, 2008; Zure Bonnie, nire Clyde - Tu Bonni, mi Clyde, 2010) y de ensayo (11 urte orgasmorik gabe. Mulder, Scully eta errepresioaren arketipo erromantikoak telebistan - 11 años sin orgasmos. Mulder, Scully y los arketipos románticos de la represión en la televisión, 2011). Su novela Nora ha despertado interés entre distintos tipos de públicos: ubicada en Bilbao refleja la situación política mundial, pero ante todo amores imposibles, casualidades inexplicables y cuentos. 
EN BÚSQUEDA DE HUELLAS PROPIAS: LITERATURA VASCA CONTEMPORÁNEA ESCRITA POR MUJERES

Garazi Goia (1978) quien no reside en el País Vasco sino en Londres, es autora de tres novelas: Bi hitz - Dos palabras, 2008; Orgasmus, 2010 y Txartel bat (des)herrira (Una tarjeta al (des)tierro, 2013). Su primera novela tiene como escenario distintas capitales europeas en las que la protagonista intenta reponerse de una decepcionante experiencia amorosa.

La autora Irati Elorrieta (1979), quien actualmente trabaja en Alemania, en su novela Burbuilak (Las burbujas, 2008) cuestiona la identidad nacional.

Katixa Agirre (1981) se inició escribiendo los textos de novela infantil y juvenil, no obstante ha llamado la atención de distintos públicos con las novelas de adultos: Sua falta zaigu (Echamos de menos el fuego 2007), Habitat (Habitat, 2009) y Atertu arte itxaron (La larga marcha, 2015). El último título es una road-novel que describe el viaje de una pareja por el País Vasco, el paisaje, la situación politica pasada y actual, pero sobre todo los cambios que sufre la protagonista a lo largo del viaje.

Uxue Alberdi (1984) es autora de narración tanto para el público adulto (Aulki bat elurretan - Una silla en la nieve, 2007; Aulki jokoa - El juego de las sillas, 2009; Euli-giro - El ambiente de moscas, 2013), como para el público jóven (Txikitzen zaretenean - Cuando os hacéis pequeños, 2013; Ezin dut eta zer? - No puedo, ¿y que?, 2011; Marizikina naiz eta zer - Soy una Marikochina, ¿y que?, 2012; Zure denboraren truke - A cambio de tu tiempo, 2012). Las protagonistas de sus relatos para adultos suelen ser mujeres quienes están limitadas por el ambiente enrarecido, casi surrealista, en el que viven las situaciones de enfermedad, peligro, muerte o tradición; sus cuentos infantiles se inscriben dentro del marco de la literatura que desafía los tópicos de diversa índole (roles sexuales, independencia de los niños).

\section{Literatura de mujeres que en Euskadi escriben en castellano}

Siguiendo a la ya citada Estibalitz Ezkerra, ${ }^{6}$ entre las mujeres que escriben en castellano se encuentran la autora de los bestsellers Toti Martínez de Lezea, Paloma Diaz-Más, Luisa Etxenique, Espido Freire, Julia Otxoa, Eli Tolaretxipi y Asun Balzola, a los que habría que añadir también

$6 \quad$ Las citas en este apartado provenen de su ensayo "Apostillas a las literaturas de los Vascos", publicado en www. basqueliterature.com 
Dolores Redondo, otra escritora con mucho éxito tanto a nivel nacional como internacional, la actual presidenta de la Asociación de Escritores de Euskadi María Eugenia Salaverri y Aixa de la Cruz.

Asun Balzola (1942-2006) fue una ilustradora reconocida, también autora de los textos de literatura infantil. La primera obra que escribió e ilustró ella misma, Historia de un erizo (1978), obtuvo el Premio Nacional de ilustración. Otros de sus trabajos son: Santino el pastelero (1986), Ala de mosca (1989), la serie dedicada a Munia (Munia y la luna, Los zapatos de Munia, Munia y la señora Piltronera, Munia y los hallazgos) y Lacazadora de Indiana Jones, con el que recibió el Premio Euskadi en 1990. Toti Martínez de Lezea (1949) empezó a publicar bastante tarde, pues su primer libro La calle de la judería salió en 1998 y a este le siguieron otras diecinueve novelas, once textos de literatura infantil y otros tres títulos de la literatura juvenil.

La producción poética de Julia Otxoa (1953) comprende Composición entre la luz y la sombra (1978), Luz del aire (1982), Cuaderno de bitácora (1985), Centauro (1985), Antología poética (1986), y La edad de los bárbaros (1997). Su obra parte de la tradición vasca, guarda un vínculo especial con la naturaleza y no deja de ser socialmente comprometida.

Paloma Diaz-Más (1954) es una experta en la cultura y literatura sefardi, fue profesora de la literatura de los Siglos de Oro en la Universidad del País Vasco. También es autora de varias novelas históricas: Biografías de genios, traidores, sabios y suicidas (1973), El rapto del Santo Grial (1984), Tras las huellas de Artorius (1985), El sueño de Venecia (1992), Como un libro cerrado (2005), Lo que aprendemos de los gatos (2014), cuentos (Nuestro milenio, 1987), obra teatral y libro de viajes. En el año 2000 recibió el Premio Euskadi de literatura en castellano por la novela La tierra fértil (1999).

Luisa Etxenike (1957) ha publicado las novelas El detective de sonidos (2011), El ángulo ciego (2009), Los peces negros (2005), Vino (2000), El mal más grave (1997) y Efectos secundarios (1996), las colecciones de relatos Ejercicios de duelo (2001), y La historia de amor de Margarita Maura (1990), y el poemario El arte de la pesca (2015). La narrativa de Etxenike es fragmentaria también en las novelas y los temas que le interesan las relaciones familiares y amorosos. La novela El ángulo ciego tiene 
EN BÚSQUEDA DE HUELLAS PROPIAS: LITERATURA VASCA CONTEMPORÁNEA ESCRITA POR MUJERES

como protagonista a un joven cuyo padre, guardaespaldas de profesión, ha sido asesinado por ETA.

Menos extensa, pero muy interesante es la obra de María EugeniaSalaverri (1957), autora de dos colecciones de relatos ¿Por qué te ríes? (2004), Un tango para tres hermanas (1997) y un libro de poemas Retrato de un pájaro (1978), quien en sus cuentos revela la incapacidad de comunicación en distintas facetas de la sociedad actual vasca.

Eli Tolaretxipi (1962) es autora con una obra "intensa" que se descubre con un primer libro en 1999, titulado Amor muerto, Naturaleza muerta, "donde dibuja un mundo de sentimientos con clarividencia." Posteriormente ha publicado Los lazos delnúmero (2003).

Dolores Redondo (1969) es autora de bestsellers más recientes. Su trilogía de Baztán (El guardián invisible, 2013; El legado de los huesos, 2013; Ofrenda en la tormenta, 2014) es una novela negra, en la que la detective tiene que enfrentarse a sus propios fantasmas y a aquella sociedad vasca de que intentaba huir.

Espido Freire (1974) es autora de novelas Irlanda (1998), Donde siempre es octubre (1999), Melocotones helados (1999), Diabulus in Musica (2001), Nos espera la noche (2003), La diosa del pubis azul (2005), Soria Moria (2007), Hijos del fin del mundo: de Roncesvalles a Finisterre (2009), La flor del Norte (2011), cuentos cortos y ensayos. Su obra plantea, sostiene Ezkerra, "la ambigüedad de las apariencias, el bien según los valores sociales y la fascinación por el mal, mediante mundos mágicos o en la vida cotidiana, creando universos muy complejos y tiempos inexistentes que exigen esfuerzo al lector."

Otra autora de narrativa (novelas: Cuando fuimos los mejores, 2007; De música ligera, 2009 y cuentos cortos: Modelos animales, 2015) es Aixa de la Cruz (1988) a quien Antonio Gala describió como "cara inocente, pluma sucia," y quien afirma que "la función de la literatura no es apartar la mirada sino lograr que la violencia vuelva a decirnos algo." (Cruz 2015). En Modelos animales, por ejemplo, "la violencia irrumpe de manera inesperada en contextos que no deberían augurarla, o es ejercida por personajes de quienes no se espera,"7 en familia, en el hospital, entre amigos.

$7 \quad$ Cito el texto de la contraportada del libro. 


\section{Autoras que escriben en francés}

Entre las autoras vascas que escriben en francés Ezkerra Vegas destaca sobre todo a Marie Darrieussecq (Baiona, 1969) quien es hoy en día una de las autoras más reconocidas en Francia. En sus obras priman los personajes femeninos, las relaciones de pareja y entre madres e hijos. Son motivos recurrentes las desapariciones, la ausencia, los fantasmas o la pérdida de la memoria. Las cuestiones de identidad y pertenencia también son una constante en sus trabajos, ya que la escritora considera que "escribir es... un humanismo: se trata de abandonar la piel de una e ir hacia el Otro". Hasta la fecha, lleva publicados los siguientes títulos: Truismes (1996), Naissance des fantômes (1998), Le mal demer (1999), Précisions sur les vagues (1999), La Plage (2000), Brefséjour chez les vivants (2001), Le bébé (2002), White (2003), Le pays (2005), Zoo (2006), Tom est mort (2007), Tristes Pontiques (2008) y la obra teatral Le Musée de la mer (2009).

Desde hace unos años, también afirma Ezkerra Vegas, la editorial Gatuzain lleva a cabo una labor clave para dar a conocer la obra de autores vascos que se expresan en francés. En su catálogo encontramos la exitosa primera novela de Marie José Basurco (San Juan de Luz, 1947), L'Éxilée (1997), a la que han seguido otros tres títulos de la misma escritora: Nouvelles d'ici (1987), Retour d'exil (1997) y Sois forte, Lucia (2007). A través de la propia Gatuzain vio la luz LesBohémiens (2009) de Nicole Lougarot (Gotein-Libarrenx, Zuberoa, 1963).

A modo de conclusión recapitulemos los rasgos más destacados de la presente radiografia. Las literaturas vascas de mujeres en la actualidad se ubican dentro de tres sistemas literarios: el que se desarrolla en euskera (15 autoras), el del castellano (10 autoras) y el francés (3 autoras). A pesar de expresarse en tres lenguas distintas, los temas más tratados son los de distintos tipos de relaciones. Además de destacar las similitudes temáticas de las autoras mencionadas, llama mucho la atención la mirada aguda con la que las autoras llegan a disecar las relaciones humanas que bien ubican directamente en la sociedad actual (como es el caso de Itxaro Borda), bien enfocan desde el punto de vista más intimista (Miren Agur Meabe) para hablar de distintas formas de alienación tanto a nivel del lenguaje (Miren 
EN BÚSQUEDA DE HUELLAS PROPIAS: LITERATURA VASCA CONTEMPORÁNEA ESCRITA POR MUJERES

Agur Meabe), la estructura del relato (Luisa Etxenike), los temas tratados (Eider Rodríguez, Jasone Osoro, Aixa de la Cruz, Espido Freire). En las obras predomina la narrativa, muchas autoras cultivan también la literatura infantil y juvenil. También es significativo que entre las autoras mencionadas la mayoría compaginan su labor de escritoras con otras actividades culturales: la traducción, la docencia, el periodismo, la ilustración, etc.

\section{BIBLIOGRAFIA}

Aldekoa, Iñaki. Historia de la literatura vasca. Donostia: Erein, 2004. Inprimatu. Aulestia, G. "Historiografía literaria vasca". Sancho el Sabio, 2 (1992): 51-58. Inprimatu.

Ayerbe Sudupe, Mikel. Euskal narratiba garaikidea: katalogo bat. Donostia/San Sebastián: Etxepare Euskal Institutua, 2012. Inprimatu.

Ezkerra Vegas, Estibalitz: Apostillas a las literaturas de los Vascos. Web. basqueliterature.com. 26.5.2016.

Guillén, Claudio. Las múltiples moradas: ensayo de literatura comparada. Barcelona: Tusquets, 1998. Impreso.

Juarsti, Jon. Literatura vasca. Madrid: Taurus, 1987. Impreso.

Larraurari, Eva. La hora global de la literatura en euskera. Web. 01.4.2016. http:// cultura.elpais.com/cultura/2013/04/25/ actualidad/1366884407_835104.html

Lasagabaster, Jesús María. Literatura vasca. Letras españolas: 1976-1986. Madrid: Castalia, 1987, 283-303. Impreso.

Mitxelena, Koldo. "Euskal literaturaren bereizgarri orokorrak." Michelena, Luis. Koldo Mitxelena gure artean. Zarautz: Alberdania, 2001, 53-72. Inprimatu.

Olaziregi, Mari José. "Bernando Atxaga o la seducción de los lectores vascos". López Criado, Fidel (ed.). Literatura y sociedad, el papel de la literatura en el siglo XX. La Coruña: Universidad La Coruña, 2001, 463-474. Impreso.

Pregelj, Barbara, i Olaziregi, Mari José. "Zlata doba, železna doba ali doba literature? : vprašanje periodizacije, reformacije, protireformacije $v$ luči opozicije med vizualno-ustnim ter pisnim skozi optiko slovenske, baskovske in španske literarne zgodovine". Bjelčevič, Aleksander (ed.). Reformacija na Slovenskem. (ob 500-letnici Trubarjevega rojstva). Ljubljana: Znanstvena založba Filozofske fakultete, 2010, 147-157. Tiskano. 
Pregelj, Barbara. "Zgodba o Maider, mami, babici --- in mački". Landa, Mariasun. Ko so mačke tako same. Medvode: Malinc, 2013, 115123. Tiskano.

Salaberri, Patxi. Iraupena eta lekukotasuna. Euskal literatura idatzia 1900 arte. Donostia: Elkar, 2002. Inprimatu.

Zukaro, Martina. "Aixa de la Cruz 'La función de la literatura no es apartar la mirada sino lograr que la violencia vuelva a decirnos algo'." Pliego suelto. Revista de literatura y alrededores. Web. 28.5.2016.

\section{Barbara Pregelj}

\section{LOOKING FOR THEIR OWN TRACKS: CONTEMPORARY BASQUE WOMEN'S LITERATURE}

\section{Summary}

The article delivers a panoramic view of literatures written by women authors in the Basque Country that write in Basque, Spanish and French. Considering the thematic analysis of literary works, the article points out the principal similarities and differences between authors belonging to three different literary systems, established by the use of the respective languages.

Keywords: Basque literatures, women's literatures, thematic analysis, Basque, Spanish, French. 